\title{
A CLÁUSULA SOCIAL NA OMC: \\ POR UMA INTER-RELAÇÃO EFETIVA ENTRE OMC E OIT E O RESPEITO AOS DIREITOS FUNDAMENTAIS DOS TRABALHADORES
}

\author{
THE SOCIAL CLAUSE IN THE OMC: \\ FOR A PERMANENT INTERRELATION BETWEEN OMC AND OIT \\ AND THE RESPECT TO THE BASIC RIGHTS OF THE WORKERS
}

Maria do Socorro Azevedo de Queiroz"

\begin{abstract}
Resumo: A inclusão de cláusula social no âmbito da OMC, como forma de eliminar condições de trabalho degradantes nos países em desenvolvimento, é tema que vem sendo exaustivamente discutido dentro das relações internacionais do comércio. Os países desenvolvidos acusam os países em desenvolvimento de "dumping sociaP' e propugnam por restrições no comércio internacional aos países que não consagram um padrão mínimo de exigências para a classe trabalhadora. Os países em desenvolvimento acusam os países desenvolvidos de se utilizarem desse discurso apenas como forma de proteger seus mercados internos. Os argumentos de ambos são plausíveis, por isso, é necessário encontrar um termo médio, que inter-relacione OIT e OMC no sentido de se proteger os trabalhadores envolvidos no processo de produção para o mercado internacional, ao mesmo tempo, que impeça os países desenvolvidos de se aproveitarem da cláusula social para imporem barreiras protecionistas, prejudicando os países em desenvolvimento.
\end{abstract}

Palavras-chave: Cláusula social. Comércio internacional. Padrão trabalhista. Inter-relação e princípios fundamentais.

\begin{abstract}
The inclusion of social clause in the scope of the OMC, as form to eliminate lower conditions of work in the developing countries, is subject that comes exhaustingly being argued inside of the international relations of the commerce. The developed countries accuse the social developing countries with "dumping" and advocate for restrictions in the international trade to the countries that do not consecrate a minimum standard of requirements for the working class. The developing countries accuse the developed countries of waking use of this speech as form to
\end{abstract}

Auditora-Fiscal do Trabalho, Professora do curso de Direito da NOVAFAPI-PI e mestranda em Direitos Fundamentais na ULBRA-RS. email: socorroq@hotmail.com. 
protect their domestic markets. The arguments of both are reasonable, therefore, it is necessary to find an term intermediate, that interrelates OIT and OMC in the direction of protecting the involved workers in the process of production for the international market, at the same time, that it hinders the developed countries of tanking advantage of the social clause to impose protectionistic barriers, harming the developing countries.

Keywords: Social clause. Working standards. International trade. Interrelation. Basic principles.

\section{INTRODUÇÃO}

O tema apresentado vem de uma antiga discussão a respeito de uma justa concorrência nas relações internacionais de comércio, muito mais do que uma preocupação direta com a classe trabalhadora envolvida na produção dos bens levados ao comércio internacional. Nesta Seara, apresenta-se a questão do padrão trabalhista a ser adotado por todos os países que concorrem no comércio internacional, como forma de tentar minorar as vantagens dos determinados países, que possuem mão-de-obra abundante, os que estão em desenvolvimento, sobre os que mantêm um padrão mais elevado de direitos trabalhistas, os países desenvolvidos, entre eles Japão, Estados Unidos e países da Europa continental.

Apresenta-se como referência histórica (REGIS, 1997), que as primeiras preocupações com a padronização das questões trabalhistas vêm das conseqüências da Revolução Industrial, séc. XIX, na Europa, quando a liberdade de contratar mão-de-obra sem qualquer intervenção estatal aviltava as condições dos trabalhadores, com o objetivo de obter vantagens comerciais na relação das trocas de manufaturas. Pressionados por movimentos da classe operária, que se organizava em busca de melhores condições no ambiente de trabalho, melhores salários, redução da jornada de trabalho, eliminação do trabalho infantil, redução do trabalho da mulher e direitos de associação e greve, os países exigem que o avanço destas questões se desse de forma a abranger todos os países envolvidos no comércio internacional.

Nesse sentido, foi criada a Organização Internacional de Trabalho (OIT) por iniciativa da Suíça, acompanhada da Alemanha, sendo os primeiros países a legislarem internamente sobre questões trabalhistas. Nesse sentido, era necessário que as normas sobre trabalho fossem adotadas por todos os outros países, sob pena de prejuízos nas relações comerciais pelos os países que avançavam nestas questões. Esse ponto central, de proteção dos trabalhadores e sua influência no campo das relações internacionais de comércio, atravessou mais de um século e 
está presente ainda nas discussões da Organização internacional do Comércio OMC.

O presente trabalho aborda, inicialmente, a dimensão social do liberalismo, mostrando que as questões sociais permeavam as idéias que deflagaram o liberalismo econômico e social, incluindo a necessidade de bem assalariar o trabalhador, até chegar ao paradigma do Estado Democrático de Direito. Após, abordaremos a criação da OIT e sua atuação presente na melhoria das condições dos trabalhadores no mundo. Em seqüência, apresentaremos o histórico da OMC e as tentativas de inclusão do que se chama de cláusula social no âmbito das regulações internacionais do comércio, bem como a possibilidade de interrelacionar OIT e OMC, no sentido, não de estabelecer um padrão único a viger em todos os países envolvidos nas trocas comerciais, mas como forma de eliminar as condições degradantes de trabalho, ainda existentes, principalmente em países em desenvolvimento, tais como trabalho escravo e infantil.

\section{A VISÃO DO SOCIAL NAS IDÉIAS LIBERAIS E COMO A QUESTÃO CHEGA AO ESTADO SOCIAL E DEMOCRÁTICO DE DIREITO}

Não é possível discorrer sobre comércio internacional e relações de trabalho sem situar o sujeito de direito ao longo da história, desde a formação do Estado moderno. O Estado liberal surge como movimento de ruptura ao antigo regime, com suporte na concepção filosófica de que o homem é o fim de toda organização política, da sociedade e do direito. Essa concepção se estabelece a partir da luta pela tolerância religiosa e sobre as posições defendidas pelo jus-naturalismo, nos sécs. XVII e XVIII, de formação das sociedades através de um contrato social.

A idéia de sociedade estatal convencional rompe com o pensamento clássico, do homem naturalmente social de Aristóteles, admitindo que não a natureza do homem, mas sua vontade, que, reunidas, constituiu o Estado e este se constitui para garantir os direitos de liberdade propriedade, que os homens possuem ainda no estado de natureza, mas que deles não gozam por completa desorganização e império da força individual.

Interessante notar, como se apresenta abaixo, que a formação do Estado liberal se apoiou em correntes do pensamento que defendiam os direitos de liberdade e propriedade, absolutamente, contra a interferência estatal, ao mesmo tempo em que não desconheciam a importância sobre a harmonia social desses direitos, nem sua dimensão moral e ética, podendo mesmo vislumbrar uma preocupação quanto à dimensão social destes direitos, que não podiam ser invocados de forma abusiva e para prejudicar outras pessoas.

$\mathrm{Na}$ visão de Locke (1983), o acesso à propriedade se dava pelo trabalho. 
Assim afirma que a natureza determinou bem o tamanho da propriedade pela quantidade de trabalho do homem e necessidade da vida. Nenhum trabalho podia dominar tudo ou de tudo apropriar-se. Já pregava a harmonização dos direitos individuais com os sociais. Outro pensador que inspirou a criação do Estado moderno, Kant, trazia em seu pensamento a idéia central de harmonização dos direitos, a idéia da inter-subjetividade da liberdade, partindo da concepção de que somente um homem é livre se todos também forem livres.

No campo da economia, Adam Smith, pai do liberalismo econômico, e a quem recorrem os defensores do livre comércio, apesar de se ressaltar o bem estar individual, nunca defendeu o interesse individual de forma absoluta, independente de qualquer restrição (LOPES, 2006). Admitia a intervenção do Estado na economia para assegurar o cumprimento dos contratos e prevenir as fraudes e para realizar obras de interesse público.

Em A Riqueza das Nações, escrito em 1776, defendeu o justo salário, que deveria ser suficiente para a manutenção dos trabalhadores e de sua família: "Um homem tem sempre que viver de seu trabalho e o salário que também tem, pelo menos, deve ser suficiente para mantê-lo". (SMITH, 1999, p. 43). O pai do liberalismo econômico já propugnava por condições dignas do trabalhado no campo da concorrência comercial. O único problema de seu pensamento é que Adam Smith acreditava que os fenômenos econômicos seguiam uma ordem natural, a qual propiciava uma harmonia universal, de forma que o bem podia advir mesmo do mal, afirmando que, mesmo buscando seus próprios interesses, os homens são orientados a fazerem o bem, conduzidos por uma "mão invisível", o que denota uma forte confiança na ordem espontânea das coisas.

Mas o tempo e a caminhada da humanidade se encarregaram de mostrar o contrário e o quadro que se segue à Revolução Industrial, com a liberdade de contratar no campo das relações do trabalho, é de exploração e degradação das condições de trabalho, como forma de competir no mercado econômico e gerar lucratividade. É a primeira demonstração de que crescimento econômico não é requisito suficiente para distribuição de riquezas.

À crise do Estado liberal, que não mais consegue atender aos anseios de uma sociedade, segue-se a exigência de um Estado providência, que se volta à garantia de uma igualdade fática no campo dos direitos. A construção do Estado social é uma reação aos postulados liberais por parte dos movimentos defensores da classe operária. São os efeitos da Revolução Industrial, aliados à concepção de Estado abstencionista, o foco do combate do pensamento voltado à busca de igualdade fática, no que se refere à distribuição das riquezas sociais.

Três vertentes de pensamento se destacam neste período, trazendo à luz, a 
prioridade, ou em alguns casos, a mediação entre o social e o individual. $\mathrm{O}$ materialismo histórico de Karl Marx traz a idéia de homem concreto, afirmando que as relações de produção estruturam a sociedade e determinam a cultura, a política e a consciência social e que somente uma revolução, que levaria a classe operária ao poder, pondo fim à propriedade privada, libertaria o homem da alienação a que foi submetido pelo individualismo extremo. Marx, em seu radicalismo, criticava a corrente suave do socialismo que acreditava na mudança por meio de um projeto de reestruturação das instituições sociais e políticas. Sua crítica cabia a Comte, Durkheim e Stuart Mill.

Comte, como positivista, defendia que a partir do estudo das leis sociais, é possível se estabelecer um sistema de idéias científicas que realizassem a reorganização social. Ao contrário de Comte, que entendia ser a solidariedade social espontânea, Durkheim a entendia como orgânica, característica das sociedades mais avançadas, por meio da divisão do trabalho. Durkheim destaca a individualidade e vê a liberdade e a propriedade privada como parte dela, porém não podem ser exercidas sem a consideração do social.

No entanto, são as idéias sociais liberais de Stuart Mill que tenta conciliar a liberdade individual com os interesses sociais, no que ele chama de justiça social. Mill afirmava que o positivismo científico anulava o indivíduo, pois a liberdade deveria favorecer o dissenso e a luta contra a opressão. Mill trazia a idéia de liberdade de Kant, defendendo que a liberdade não podia causar danos aos outros, nem impedir que os outros exerçam a mesma liberdade.

Pelas idéias apresentadas no campo das ciências sociais, denota-se a preocupação em colocar a sociedade acima do interesse individual e a limitar a liberdade individual em satisfação da liberdade social. São sob estas idéias e das repercussões da Encíclica Rerum Novarum, 1891, do papa Leão XIII, que se constroem o Estado social, voltada a representar uma providência para os trabalhadores, intervindo nas relações entre capital e trabalho uma relação voltada ao interesse social.

Os direitos sociais, em especial dos trabalhadores, consolidam-se no Estado social, passando a integrar os direitos fundamentais inicialmente nas Constituições do México, 1917, e de Weimar, 1919. Nesta perspectiva, relativizam-se a delimitação dos espaços público e privado, sendo este instrumento de realização de justiça social. No Estado social, o interesse da sociedade se sobrepõe ao interesse do indivíduo.

É nesse clima que surge a Organização Internacional do Trabalho (OIT), em 1919, a partir do Tratado de Versales, que pôs fim a I Guerra Mundial. A OIT é uma instituição internacional de promoção da defesa dos trabalhadores, atuando 
de forma a convencer os países membros das nações Unidas a aderirem a um padrão de condições de trabalhado, voltado a tratar o trabalhador como indivíduo primeiro, para quem se volta o Estado e o mercado. A criação da OIT funda-se numa preocupação humanitária, no sentido de preservara dignidade dos trabalhadores no mundo.

Mas o Estado social não se sustentou perante as exigências de uma sociedade complexa e plural como a contemporânea, que necessitava de um equilíbrio entre o privado e o público, o individual e o social, das relações de produção e da justiça social, encontrando abrigo na construção de um novo paradigma que surge da experiência do Estado liberal e com o fracasso do Estado social: o paradigma do Estado Democrático de Direito. Este é uma construção da teoria constitucional que busca pela democracia conformar liberdade e igualdade, capital e trabalho.

É a partir da idéia de inter-relação entre o capital e justiça social, que se defende a inter-relação de comércio e direitos trabalhistas, de abertura e mundialização das relações comerciais, com reflexo direto na melhoria de padrões de vida dos trabalhadores envolvidos nesta cadeia de produção, com base no princípio de que as ações individuais devem estar voltadas ao interesse social, que as relações comerciais devem ter como foco sua função social, não privilegiando pessoas, países ou grupos organizados individualmente, mas as comunidades como um todo.

Nesta seara, é impensável um espaço onde se privilegie apenas as relações de comércio sem a preocupação com a cadeia produtiva, dentro dela os trabalhadores e o meio ambiente, por exemplo. É impensável uma separação radical entre o mundo do comércio, com suas regras próprias, e o mundo do trabalho, com suas regras próprias e órgãos reguladores próprios atuando separadamente. Trabalho e comércio estão tão interligados que impossível pensar um sem o outro no mundo atual de abertura internacional para as relações comerciais.

É com base neste imbricamento, que passaremos a estudar a questão da inclusão da cláusula social no âmbito da OMC e a participação da OIT neste processo. Ao final tentaremos apresentar uma proposta que intente eliminar o que chamamos de condições degradantes de trabalho, com reservas para que esta solução não descambe para a utilização protecionista por parte dos países desenvolvidos.

\section{OIT E OS PRINCÍPIOS FUNDAMENTAIS}

A motivação da criação da OIT vem das preocupações com o quadro de exploração que se segue à Revolução Industrial, com conflitos entre a classe 
trabalhadora e os proprietários dos meios de produção. Jornada de trabalho exaustiva, trabalho noturno e insalubre para menores, exploração da mão-deobra infantil e das mulheres, foram temas que chamaram a atenção do mundo, no sentido de que era necessário um disciplinamento mundial dessas questões, por se tratar de desafios aos direitos do homem. "A razão determinante para a criação da OIT foi de ordem humanitária”, (DI SENA JÚNIOR, 2003, p. 133). O objetivo era criar uma consciência mundial contra a exploração dos trabalhadores pelos empresários que, ávidos por melhor competir no mercado e obter lucros, aviltavam as condições de trabalho e dos trabalhadores.

Então, a OIT se institui com o objetivo de melhorar as condições de trabalho no mundo, eliminando as formas degradantes e injustas de trabalho a que eram submetidos os trabalhadores na época. Di Sena Júnior (2003, p. 135) apresenta duas outras motivações para a criação da OIT: de ordem política, pois a crescente degradação das condições de trabalho, decorrente da evolução do processo de industrialização, causaria como de fato já estava causando, instabilidade social e de ordem econômica, sendo que os países que passavam a adotar melhores padrões trabalhistas sentiam-se injustiçados nas relações comerciais, por se colocarem em desvantagem em relação àqueles que não adotavam os mesmos padrões. $\mathrm{O}$ último motivo ainda é o mesmo argumento adotado pelos países desenvolvidos que defendem a inclusão da cláusula social no âmbito da Organização Internacional do Comércio (OMC) com respectiva sanção em caso de não cumprimento. É a discussão que apresentaremos mais adiante.

A OIT é uma agência da Organização das Nações Unidas (ONU) especializada em questões trabalhistas. Criada em 1919, como já referido, pelo Tratado de Versalles que pôs fim a $1^{\circ}$ Guerra Mundial. Sua nova Constituição foi aprovada em 1946, na 29º reunião da Conferência Internacional do Trabalho, em Montreal, Canadá, mantendo-se como instituição chave para o estabelecimento de melhores condições de trabalho nos países membros, conforme anuncia em seu Preâmbulo:

Considerando que existem condições de trabalho que implicam, para um grande número de indivíduos, miséria, privações, e que o descontentamento que daí decorre põe em perigo a paz e a harmonia universais, e considerando que é urgente melhorar essas condições no que se refere, por exemplo, à regulamentação das horas de trabalho, à fixação de uma duração máxima do dia e da semana de trabalho, do recrutamento da mão-de-obra, à luta contra o desemprego, à garantia de um salário que assegure condições de existência convenientes, à proteção dos trabalhadores contra as moléstias graves ou profissionais e acidentes do trabalho, à proteção das crianças, dos adolescentes e das mulheres, às pensões da velhice e da invalidez, à defesa dos interesses dos trabalhadores empregados no estrangeiro, à afirmação do princípio 
"para igual trabalho mesmo salário”, à afirmação do princípio de liberdade sindical, à organização do ensino profissional e técnico, e outras medidas análogas;

Considerando que a não adoção por qualquer nação de um regime de trabalho realmente humano cria obstáculos aos esforços de outras nações desejosas de melhorar a sorte dos trabalhadores nos seus próprios territórios... ${ }^{33}$ Texto em vigor da Constituição da OIT desde 20.04.1948 em emenda aprovada pela 29º reunião da Conferência Internacional do Trabalho, em Montreal, Canadá, 1946, substitui a adotada em 1919, que sofreu três emendas anteriores, em 1922, 1934 e 1945. O texto atual foi ratificado pelo Brasil, ainda em 1948. Informações em SENA, Roberto Di Junior. Comércio Internacional \& Globalização: a cláusula social na OMC, 2003.

Como instituição que atua na seara trabalhista, ela é organizada de forma tripartite, com a composição de seus órgãos por representantes do Governo, trabalhadores e empregadores, sendo de 50\% do Governo, 25\% dos trabalhadores e 25\% dos empregadores. Estrutura-se em três órgãos: a Conferência - reúne-se anualmente em Genebra e é composta por todos os Estados-membros, sendo sua competência principal estabelecer normas internacionais de trabalho através de Convenções e Recomendações. Outro órgão da OIT é o Conselho de Administração - reúne-se três vezes ao ano em genebra e é responsável pelas as decisões políticas e executivas. A repartição Internacional do Trabalho funciona como uma secretaria permanente da OIT, organizando as atividades da instituição.

Embora a OIT seja um órgão que atua internacionalmente captando reivindicações, fazendo levantamento de situações degradantes de trabalho, acompanhando o progresso tecnológico e o desenvolvimento do comércio mundial e seus impactos nas condições de trabalho, sua ingerência junto as Estadosmembros se dá apenas de forma negocial. A Organização não dispõe de nenhum mecanismo sancionatório quando os Estados-membros não cumprem as Convenções que adota sequer os Estados-membros são obrigados a retificarem suas Convenções, atuando mais de forma promocional e pelo convencimento.

Uma vez aprovada uma Convenção pela Conferência Internacional do Trabalho, ela só entra em vigor após um ano de apresentada duas ratificações: quer dizer se nenhum país ratificar a Convenção aprovada, ela não entrará em vigor em nível internacional e mesmo recebendo a duas ratificações e percorrido o prazo para sua vigência no campo internacional, nenhum outro Estado membro, além dos dois primeiros que ratificaram a Convenção, é obrigado a ratificá-la, a despeito de ter participado de sua aprovação.

Cabe ainda destacar que a ratificação das Convenções da OIT não assegura sua implementação direta pelo Estado-membro. Como bem observa Di Sena Júnior (2003, p. 142) o fato do de um país ratificar qualquer Convenção da OIT não implica em seu cumprimento, sendo que a implementação interna depende 
da vontade do Estado, que não sofre nenhuma sanção por parte da OIT pela por não ajustar sua conduta conforme as Convenções por ele ratificadas, que conta somente com a opinião pública para coagir o estado transgressor.

Mas o procedimento de descumprimento das Convenções da OIT não é tão sem efeito assim. Os membros da Organização podem denunciar determinado Estado por não estar cumprindo determinada Convenção, desde que os dois Estados-membros hajam ratificada a Convenção em questão. Conforme o art. 26 da Constituição da OIT, a queixa é encaminhada à Repartição Internacional do Trabalho, que repassa a reclamação ao Conselho de Administração que, por sua vez, constituirá uma Comissão de Inquérito. Esta examinará a queixa, elaborando um relatório minucioso sobre a questão e apresentará medidas recomendatórias ao Estado-membro alvo da queixa, concedendo prazo para ajuste dos termos descumpridos, no sentido de solucionar a controvérsia e dar uma resposta ao Estado-membro queixoso. O relatório será repassado pelo Diretor-Geral da RIT - Repartição Internacional do Trabalho - aos Governos interessados no litígio, que devem manifestar se aceitam ou não as recomendações adotadas ou se preferem levar o caso à Corte Internacional de Justiça da ONU - Organização das Nações Unidas.

As normas convencionais da OIT ganharam reforço com a Declaração Universal dos Direitos Humanos, em 10 de dezembro de 1948, ao estabelecer os direitos primeiros e inegociáveis da pessoa humana, que os possui pela simples condição de ser pessoa humana. Esses direitos, para Flávia Piovesan, são universais e indivisíveis, não podendo se dissociar os individuais dos sociais, defendendo, dessa forma, uma inter-relação entre liberdade econômica e direitos sociais dos trabalhadores. A autora observa um avanço da atuação da OIT, a partir do Pacto Internacional dos direitos Econômicos, Sociais e Culturais, de 1966.

O Pacto Internacional dos Direitos Econômicos, Sociais e Culturais, que atualmente contempla a adesão de 145 Estados-Partes, enuncia um extenso catálogo de direitos, que inclui o direito ao trabalho e à justa remuneração, o direito de formar e a filiarse a sindicatos, o direito a um nível de vida adequado... Desse modo, a efetivação dos direitos econômicos, sociais e culturais não é apenas uma obrigação moral dos estados, mas uma obrigação jurídica... (PIOVESAN, 2003, p. 243-4).

Mas recentemente, em 1998, a OIT aprovou a Declaração dos Princípios e Direitos Fundamentais dos Trabalhadores, que em resumo expressa os termos das Convenções sobre Liberdade Sindical, Livre Associação e Negociação Coletiva (Convenções 87 e 98), Eliminação das Formas de Trabalho Forçado (Convenções 29 e 1050, Eliminação do trabalho Infantil (Convenções 138 e 182), Eliminação da Discriminação no Emprego (Convenções 100 e 111). Esta Declaração de 
Princípios Fundamentais expressa o compromisso de todos os Estados-membros de uma padronização mínima nas relações de trabalho, a prevalecer, inclusive, sobre o mercado de comércio internacional.

Mas do compromisso afirmado e expresso na Declaração de Princípios de Direitos Fundamentais dos Trabalhadores não decorre a conseqüência direta de sua implementação e respeitos por todos os Estados-membros, trazendo como resultado a melhoria no padrão de vida dos trabalhadores e a justa concorrência no mercado internacional, pois a Declaração de Princípios e as Convenções são instrumentos normativos sem eficácia vinculante, uma vez que elas não prevêem qualquer sanção por seu descumprimento.

As Convenções da OIT não correspondem às leis supranacionais capazes de ter eficácia jurídica de direito interno nos Estados-membros. Portanto, a Conferência que gera tal tratado não é o que se pode entender por um parlamento universal com poderes para impor normas aos distintos Estados, sem contar com a aceitação de sua autoridade. (SANTOS, 2004, p.34).

Apesar da juridicidade anunciada destes direitos mínimos sua efetividade depende de meios eficazes que de se garantir o cumprimento das decisões da Conferência Internacional do Trabalho e da Corte Internacional de Justiça, e esse é o problema central: é possível estabelecer sanções a nível internacional para o descumprimento dos padrões trabalhistas fundamentais? O comércio mundial pode se prestar como instrumento de coação para os Estados participantes? É o que veremos na seqüência.

\section{A CRIAÇÃO DA OMC E OS DEBATES EM TORNO DA CLÁUSULA SOCIAL}

A tentativa de criação de uma organização mundial que disciplinasse as relações internacionais de comércio data do final do segundo pós-guerra. Em de 1944, quando 44 países envolvidos no conflito mundial se reuniram em New Hampshire, Estados Unidos, com o objetivo de discutir e configurar uma estrutura que passasse a funcionar após a guerra, voltada a ajudar os países europeus arrasados pelo conflito. A reunião, conhecida como Conferência de Bretton Woods, liderada pelos Estados Unidos, resultou no acordo de criação de três instituições: Fundo Monetário internacional(FMI), o Banco Mundial de Desenvolvimento e Organização Internacional do Comércio (OIC) (THORSTENSEN, 1999).

O primeiro órgão ficou responsável pela gerência das transações financeiras e da questão monetária entre os bancos centrais dos países envolvidos no acordo. O Banco Mundial de Desenvolvimento ficou responsável por ajuda financeira para reconstrução dos países advindos da guerra, bem como pelo financiamento 
de projetos na área social. Já a OIC, que objetiva a disciplina das relações internacionais de comércio, com conseqüente liberação das fronteiras nacionais, foi configurada em 1947, na Conferência Mundial sobre Comércio e Emprego, realizada em Havana, Cuba. No entanto, a OIC não seguiu seu curso por sua não ratificação pelos Estados Unidos, restando ao General Agreement on Tariffs and Trade (GATT) - acordo assinado em Genebra, em 1947, para liberação de barreiras tarifárias entre os 23 países signatários, a tarefa a regular e acompanhar as relações mundiais do comércio.

A Carta de Havana, 1948, que então criara a OIC trazia em seu art. $7^{a}$ o compromisso dos países envolvidos com o estabelecimento de padrões justos de trabalho, sob o argumento de que condições injustas de trabalho refletiam na melhoria da produtividade e que divergência de tratamentos dos trabalhadores de um país para o outro implicava em concorrência desleal. Mas a idéia de manutenção de um patamar de igualdade no tratamento das questões trabalhistas nos países envolvidos no comércio internacional é bem mais antiga que a idéia de criação de uma instituição que disciplinasse as relações comerciais no mundo.

Em plena Revolução Industrial, séc. XVIII, a abundância de mão-de-obra na Europa, que aumentava à medida que os países se urbanizavam, trazendo as populações da zona rural para as cidades, deixava uma parte da relação entre capital e trabalhista em desvantagem no mercado, onde imperava a lei de oferta e procura. Daí a necessidade da inclusão de cláusulas sociais nos contratos de trabalho, tanto internamente, nos Estados nacionais, como, externamente, conforme a internacionalização do comércio tomasse fosse ganhando maiores dimensões.

Cita André Regis (1997, p. 02) que as primeiras iniciativas de se propor o tema de padrões trabalhistas no espaço internacional foi da Alemanha e da Suíça, sendo que estes países foram também os primeiros a regular internamente as relações entre capital e trabalho. Ainda em 1890, foi realizada, em Berlim, a primeira Conferência entre Governos para tratar de questões trabalhistas. A França e a Inglaterra, apesar de restringir as discussões ao trabalho das mulheres, crianças e adolescentes, esvaziaram a proposta, uma vez que a primeira não acatou as resoluções da Conferência e o segundo acatou, mas não as implementou. Os resultados da Conferência só não foram em vão porque ensejaram a criação da OIT, que veio acontecer em 1919, como já tratado.

Mas a discussão em torno da inclusão de padrões trabalhistas nos acordos internacionais de comércio teve o mesmo fim da OIC e os esforços em ligar padrões trabalhistas ao comércio internacional ressurgiram durante as reuniões do GATT, chamadas de rodadas de negociação, desta vez tendo como linha de frente os Estados Unidos. 
O GATT é um acordo que trata mais especificamente da redução de barreiras tarifárias, que funcionou como agência reguladora da abertura comercial para todos os países, até a criação da Organização Mundial do Comércio (OMC). Atua o GATT sob três regras principais: o tratamento da nação mais favorecida - NMF - que proíbe qualquer país discriminar qualquer outro, ou seja, as vantagens concedidas a um país devem ser abertas a todos os outros, nas mesmas condições; a do tratamento nacional, em que os produtos importados, uma vez adentrados às fronteiras do Estado devem receber o mesmo tratamento dos produtos nacionais, ou seja, deve ser considerado como nacional fosse; e a regra da redução de barreiras tarifárias por meio de negociações.

O GATT empreendeu oito rodadas de negociação até 1986, sendo a de maior importância, a última, conhecida como Rodada Uruguai, iniciada em 1986, em Punta del Leste, e concluída em 1994, em Marraqueche, com a criação da Organização Mundial do Comércio (OMC). Além de singular importância pela criação da OMC, não se limitou a isso, incluindo os setores de agricultura, têxtil, o ramo de serviços nas regras do comércio internacional, bem como estabeleceu regras sobre propriedade intelectual, além de alcançar a redução das tarifas alfandegárias para 5\%, segundo Thorstensen (1999, p. 39). Também, da Rodada Uruguai resultou a reformulação do processo de solução de controvérsia, que funcionou, a partir da OMC, dando mais agilidade e credibilidade aos conflitos comerciais entre os Estados-membros.

Ressurge na Rodada Uruguai a questão de padrões trabalhistas, com os Estados Unidos tentado abrir a discussão acompanhado da França. No entanto, a resistência dos países em desenvolvimento prosperou e a proposta dos Estados Unidos de incluir um padrão de condições de trabalho na OMC fracassou. Mas isso era só o início de uma forte discussão que perdura até hoje, colocando de um lado os Estados Unidos, que acusam os países em desenvolvimento de "dumping social, obtendo, em decorrência, vantagens comerciais sobre os países que adotam padrões trabalhistas considerados justos, e de outro, os países em desenvolvimento, dentre eles destaca-se o Brasil, que acusam os Estados Unidos de esconder propósitos protecionistas por trás de sua proposta.

O novo Palco de discussão do tema foi a Rodada Cingapura, em 1996. A Noruega alia-se aos Estados Unidos na defesa da inclusão de um padrão de condições de trabalho a ser adotado por todos os países envolvidos nas relações de comércio internacional, como forma de tornar as relações mais equilibradas. Mais uma vez fracassa a empreitada americana, conseguindo os países em desenvolvimento, com forte liderança do Brasil, fechar a questão, atribuindo a OIT o cuidado com padrões trabalhistas mais justos, deixando a OMC fora de 
qualquer interferência nas relações de trabalho dos países-membros. Em declaração ministerial, fica clara a posição da OMC quanto à adoção da cláusula social, afirmando que a questão deve ser tratada pelo organismo internacional para isso criado: a OIT.

Renovamos nossos compromissos de respeitar as normas fundamentais do trabalho, internacionalmente reconhecidas. A OIT - Organização Internacional do Trabalho - é o órgão competente para estabelecer essas normas e ocupar-se delas, e afirmando nosso apoio a sua atividade de promoção das mesmas. Consideramos que o crescimento e o desenvolvimento econômico, impulsionados pelo incremento do comércio e pela maior liberalização comercial contribuíram para a promoção dessas normas. Rechaçamos a utilização das normas de trabalho com fins de protecionismo e concordamos que não se deve em absoluto a vantagem comparativa dos países, em particular, dos países em desenvolvimento e seus baixos salários. A esse respeito tomamos nota de que as secretarias da OMC e da OIT prosseguirão com suas atuais colaborações. (OMC, DECLARAÇÃO MINISTERIAL, 1996).

A posição vencida no âmbito da OMC e que se conserva atualmente é de completa separação dos espaços das normas do mundo do trabalho e da atuação do comércio internacional. Mais cinco Rodadas de Negociação prosseguiram sem que a questão sofresse qualquer alteração. Diante da atual situação, como já abordado, de falta de efetividade das normas internacionais do trabalho, e de situações denunciadas de exploração de mão-de-obra em países em desenvolvimento, com infração às normas de direitos fundamentais dos trabalhadores, pergunta-se, então: com quem está razão?

Que é possível os países desenvolvidos utilizar barreiras comerciais por descumprimento dos direitos trabalhistas fundamentais com caráter para proteger seu mercado interno, caso seja aceita a cláusula social na OMC, não se nega. Por outro lado, é justo que países em desenvolvimento lucrem com o comércio internacional à custa da exploração vil de sua farta mão-de-obra? Entendemos também que não. Por isso, encerrar a questão separando os espaços de atuação da OIT e OMC não resolve o problema. É necessário buscar uma solução, integrando a atuação dos dois órgãos internacionais - OIT e OMC, uma vez que o comércio internacional e padrões trabalhistas estão inerentemente ligados na seqüência da cadeia produtiva.

O protecionismo dos países desenvolvidos é motivo forte de preocupação por parte dos países em desenvolvimento, mas não é motivo, sequer razoável, para se evitar medidas efetivas que assegurem o cumprimento dos direitos fundamentais dos trabalhadores no mundo. E a cláusula social, se bem inserta nos tratados internacionais de comércio e bem administrada pode render grandes frutos em benefícios de todos: Estado, empresários e trabalhadores. 


\section{O DUMPING SOCIAL: É POSSÍVEL UTILIZAR A OMC COMO INSTRUMENTO DE COAÇÃO AO CUMPRIMENTO DOS DIREITOS FUNDAMENTAIS DOS TRABALHADORES NO MUNDO?}

Para definir o que seja dumping, utilizamos o conceito de Barral (2000, p. 217), para quem "esta prática pode ser definida como a discriminação de preços entre dois mercados nacionais, entre o mercado exportador e o importador". Ocorre quando o determinado Estado coloca no mercado externo determinado produto com preço menor do que o praticado no mercado nacional. Porém, a prática do dumping somente enseja medidas antidumping, sob a guarda da regulamentação do OMC, quando além do preço praticado no mercado externo ser menor do que o praticado internamente, essa prática gere ao país importador prejuízos e que esses prejuízos estejam ligados à prática, ou seja, o país que alega o dumping praticado por outro deve demonstrar que a ação do país exportador lhe causou prejuízos e o nexo causal destes prejuízos com dumping. Somente demonstrada essa relação, o país importador prejudicado pode a impor medidas antidumping, conhecidas também como barreiras não tarifárias, tais como tarifas excepcionais ou medidas compensatórias..

A partir da prática do dumping, construiu-se a o termo dumping social, que ocorre quando determinado país exportador aufere a vantagem de preço em seus produtos no mercado internacional em decorrência da utilização de baixos padrões trabalhistas. Condenando esta prática e em busca de relações comerciais mais justas, como já apontado, os países desenvolvidos, em especial os Estados Unidos, propugnam por medidas antidumping social, com a inclusão da chamada cláusula social, que seria o estabelecimento de um padrão mínimo de condições de trabalho a ser observado pelos Estados exportadores, sob pena de imposição de barreias não tarifárias.

Os países atingidos por essas medidas, diretamente, serão os países em desenvolvimento, que acusam os defensores da cláusula social de esconder propósitos protecionistas por trás da defesa dos trabalhadores dos países do terceiro mundo. Argumentam que sua farta mão-de-obra, que proporciona baixos salários, é uma vantagem comparativa favorável em relação à tecnologia, maiores investimentos e mão-de-obra qualificada dos países desenvolvidos. Assim pensa o Governo brasileiro, que se manifesta não contrário a melhoria dos padrões trabalhistas, mas a indexação desse padrão aos acordos multilaterais da OMC.

O Governo brasileiro apóia, sem ambigüidade, o aprofundamento sobre o respeito aos direitos internacionais básicos do trabalhador nos foros apropriados - a Organização Internacional do Trabalho, a mais antiga instituição multilateral emanada da Liga das Nações, e a Comissão de Direitos Humanos. Também temos de fazer o 
nosso dever de casa em matéria social. Mas recorrer a instrumentos internacionais de política comercial não seria adequado para o tratamento das questões sociais; seria abrirmos um flanco sem qualquer garantia, se quer, de que as penalidades eventualmente impostas serviriam para impulsionar o progresso social nos países afetados. Sua utilização nesse contexto teria como conseqüência inevitável acrescentar uma arma poderosa ao arsenal protecionista que ainda existe à disposição dos países que, em nome do livre comércio (free trade) ou do comércio leal (fair trade), fecham seus mercados a nossos produtos e com isso comprometem o aumento da produção e a manutenção de empregos em setores da área agrícola e industrial. (LAMPREIA, 1996, p. 2.).

A União Européia não tem posição unificadamente definida, porém defende esforços para o estabelecimento de um padrão justo de condições do trabalho, mas sem sanção. Os Estados Unidos vão longe nessa questão, exigindo a adoção de padrões trabalhistas que abranjam até os salários, por considerar que os baixos salários afetam a concorrência leal. Entendemos que a proposta nesses termos torna-se inviável na globalização comercial atual, por diferenças econômicas e culturais, entre outras, e porque afeta as vantagens comparativas entre os Estados, princípio norteador das trocas comerciais, "segundo a qual os países devem se dedicar a produção de bens nos quais possuem vantagens comparativas e trocar o excedente por aquilo que não produzem”. (DI SENA JUNIOR, 2003, p. 124)

Segue Roberto Di Sena Junior afirmando que a vantagem da mão-de-obra barata é compensada pela vantagem de tecnologia e capital dos países mais desenvolvidos e que exigir um padrão de igualdade nas condições de trabalho, incluindo salários, requer o compartilhamento dos conhecimentos sobre tecnologia e do capital, para afastar a concorrência desleal. Com base na teoria das vantagens comparativas, os países em desenvolvimento defendem que a inclusão da cláusula social deve vir acompanhada da circulação da mão-de-obra.

O autor não acredita que a inclusão de cláusula social e sanções impostas por seu descumprimento vão resolver o problema do baixo padrão trabalhista nos países em desenvolvimento. Argumenta que estes países não mantêm estes padrões baixos deliberadamente para melhor concorrer no mercado internacional, mas "refletem a situação das economias marcadas pelo excesso de mão-de-obra pouco qualificada e pela escassez de capital”, (DI SENA JÚNIOR, 2003, p. 187), e que o impacto do livre comércio na distribuição de renda deve administrado de forma eficaz pelos Governos locais.

Roberto Di Sena Júnior afirma que o emprego de sanções comerciais para se melhorar os padrões trabalhistas acabam por prejudicar os trabalhadores dos países em desenvolvimento, errando o alvo. As restrições advindas pelo não 
cumprimento das cláusulas sociais prejudicarão o crescimento econômico, afetando o desenvolvimento e, por conseguinte, os trabalhadores. "O objetivo perseguido é justo, mas o instrumento inadequado" conclui.

A despeito dos argumentos apresentados, que exemplifica a posição dos autores cautelosos no que se refere à inclusão da cláusula social nos acordos de comércio internacional, entendemos que algo deve ser feito, ao menos quanto à exigência de cumprimento dos direitos fundamentais dos trabalhadores no mundo, atualmente os constantes na Declaração dos Princípios e Direitos Fundamentais dos Trabalhadores da OIT, sobre os quais nenhuma doutrina ou vantagem de troca deve prevalecer. E vamos além, entendemos que as relações de comércio internacional é uma ferramenta essencial a ser utilizada nesse processo diante da falta de efetividade da atuação da OIT já apresentada em capítulos anteriores.

Sem o exagero de se estabelecer um padrão mínimo de salário a ser implementado por todos os Estados-membros, entendemos ser possível uma atuação interligada entre OIT e OMC, não somente para o estabelecimento de relações comerciais mais justas, mas, e, principalmente, para uma efetivação do que é essencial ao homem que trabalha para o mercado produtor e consumidor. Certo que não é fácil essa ação interligada, uma vez que os países envolvidos no comércio internacional parecem não jogar com transparência: os países desenvolvidos discursam em favor dos trabalhadores, quando intencionam barreiras protecionistas - acusam os países contrários; os países em desenvolvimento emperram a melhoria de suas condições de trabalho, para melhor competir no mercado - acusam os defensores da cláusula social.

O jogo transparente, cooperativo e responsável tornaria a questão mais fácil. Nossa proposição é de encontrar uma solução que satisfaça os direitos mínimos dos trabalhadores - livre associação, negociação, igual oportunidade de emprego e livre escolha do trabalho - sem comprometer o crescimento econômico e o desenvolvimento e que constitua também num anteparo contra a utilização protecionista do meio. Nesses termos, entendemos que os casos que desafiam o cumprimento dos direitos fundamentais dos trabalhadores sejam levados inicialmente à OIT, para uma solução negociada entre os Estados, o queixoso e o infrator. Sem solução do problema, a questão pode ser levada à Corte Internacional de Justiça e a decisão tomada por essa Corte concederá prazo para que o Estado implemente os ajustes necessários, conforme normas da OIT.

Somente em casos de permanecer o descaso com os direitos fundamentais dos trabalhadores, o fato seria levado à OMC, com decisão já tomada pela OIT de que as relações comerciais daquele Estado podem sofrer restrições, no sentido de penalizá-lo por concorrer no mercado internacional à custa da exploração vil 
de seus trabalhadores. Essa proposta evita deixar o Estado exportador inteiramente nas mãos do Estado importador, resguardando àquele contra medidas protecionistas deste, ao mesmo tempo em que reserva aos trabalhadores dos países exportadores a esperança de ver seus direitos, já reconhecidos no âmbito internacional, efetivamente garantidos.

Propostas como essa não apresenta qualquer novidade, uma vez que o próprio GATT já prevê, em seu art. XX, que trata das exceções gerais, restrições à importação de bens produzidos por presos, podendo essas restrições ser estendidas contra o trabalho escravo, infantil e degradante, conforme constatação pela fórmula acima apresentada. Outra forma de ação é pelo Sistema de Proteção Geral (SPG) da OMC, que possibilita a concessão de redução de tarifas até o índice zero pelo país importador aos países exportadores que cumpram com determinadas exigências. O SPG também pode ser utilizado para incentivar o Estado infrator dos direitos fundamentais dos trabalhadores a fazer os ajustes necessários.

\section{CONSIDERAÇÕES FINAIS}

O presente trabalho partiu da idéia de que há direitos fundamentais dos trabalhadores; de que estes direitos já estão expressos em tratados internacionais, como exemplo a Declaração sobre Princípios Fundamentais e Direitos no Trabalho, aprovado pela a OIT em 1998; de que há transgressão a esses direitos por parte dos Estados envolvidos no comércio internacional; de que os princípios fundamentais e os direitos dos trabalhadores, apesar de reconhecidos, não contam com meios de coativos para sua observação; que, não obstante, o perigo dos padrões trabalhistas serem utilizados por países importadores de forma a proteger seus mercados internos, devam ser pensadas estratégias de inter-relação entre a OIT e a OMC, objetivando buscar mecanismos que levem os Estados exportadores a adotarem padrões trabalhistas, de exigência fundamental para os trabalhadores.

Ademais, nenhum Estado é essencialmente exportador ou importador, pois enquanto é bom exportador em determinados setores é importador em outros, o que faz com que todos se utilizem das medidas adotadas, uma vez que atuam nas duas áreas, vezes exigindo os padrões trabalhistas, quando importa produtos de terceiros, vezes outras sendo cobrado a manter os padrões trabalhistas, quando exporta para terceiros. Um dado a mais é de que grande parte do comércio internacional é feito entre empresas transnacionais, especificamente 63\% (THORSTENSEN, 1999, p. 24), e de que das 100 maiores economias do mundo, 51 são empresas multinacionais (PIOVESAN, 2003, p. 259), o que conta a favor da adoção de um padrão básico de direitos trabalhistas nestas empresas que atuam no mundo. 
Outras fórmulas podem ser pensadas a partir do que já existe ou serem criadas, o que não pode é a abertura do comércio mundial não vir acompanhada de melhorias para o setor mais importante da cadeia produtiva: os trabalhadores, pondo fim à ainda existente exploração desenfreada da mão-de-obra, que gera 12.3 milhões de pessoas vítimas de trabalho forçado em todo o mundo, sendo que os países da Ásia e do Pacífico são responsáveis por uma cota de mais de 80\% desse número, e os países da América Latina e Caribe, contribuem com mais de 10\%; e mais de 200 milhões de crianças vítimas do trabalho infantil, sendo que mais da metade se encontra no que se chama de "piores formas", entre elas a exploração sexual. ${ }^{1}$

Com a inter-relação entre padrão trabalhista e comércio internacional, ganha o mercado, com relações mais justas, e ganha os trabalhadores, por terem seus direitos fundamentais respeitados. Ademais, os direitos fundamentais dos trabalhadores são direitos mínimos, inegociáveis, sobre os quais, sequer, a eficiência econômica pode prevalecer. Nesta visão, concluímos ser tão essencial a associação entre comércio internacional e padrão mínimo trabalhista como é impensável a dissociação entre produto e trabalho.

\section{REFERÊNCIAS}

BARRAL, Welber. Medidas antidumping. In: BARRAL, Welber. (Org). O Brasil e a $O M C$ : os interesses brasileiros e as futuras negociações multilaterais. Florianópolis: Diploma Legal, 2000. p. 217-232.

BONAVIDES, Paulo. Do Estado Liberal ao Estado Social. 7. ed. Malheiros: São Paulo, 2001.

DI SENA JÚNIOR, Roberto. O Comércio internacional \& globalização: a cláusula social na OMC. Curitiba: Juruá, 2003.

HERDEGEN, Matthias. Derecho Econômico Internacional. 2. ed. Trad. Marcela Anzola. Fundação Konrad Adenauer: Biblioteca Jurídica, Deké, 1998.

HOBSBAWM, Eric. A Era dos Extremos. 2. ed. São Paulo: Companhia das Letras, 2005.

KANT, Emmanuel. Doutrina do Direito. Tradução: Edson Bini. São Paulo: Ícone, 1993.

${ }^{1}$ Dados da Organização Internacional do Trabalho - OIT. 
A cláusula social na OMC

LAMPREIA, Luiz Felipe. Algumas verdades sobre acerca da "cláusula social". 1996. Disponível em: <http://ftp.unb.br/pub/UnB/ipr/rel/discmin/1996/ 3056.pdf $>$. Acesso em: 8 jan. 2007.

LOPES, Ana Frazão de Azevedo. Empresa e Propriedade: função social e abuso de poder econômico. São Paulo: Quartier Latin, 2006.

LOCKE, Jonh. Segundo Tratado Sobre o Governo. Trad. Anoar Aiex e E. Jacy Monteiro. 3. ed. São Paulo: Abril Cultural, 1983. (Os pensadores).

ORGANIZAÇÃO INTERNACIONAL DO TRABALHO (OIT). Disponível em: 〈http:/www.oitbrasil.org.br〉. Acesso em: 5 jan. 2007.

ORGANIZACIÓN MUNDIAL DEL COMERCIO (OMC). Disponível em: <http:/www.wto.org/spanish>. Acesso em: 3 jan. 2007.

PIOVESAN. Flávia. Proteção Internacional dos Direitos Econômicos, Sociais e Culturais. In: SARLET, Ingo Wolfgang (Org.). Direitos Fundamentais Sociais. estudos comparados de direito constitucional internacional. Rio de Janeiro: Renovar, 2003. p. 233-261.

REGIS, André. Globalismo, Conflitos Norte-Sul e Agenda Social: a estratégia brasileira frente à questão do dumping social. 1997. Dissertação (Mestrado em Ciências Políticas) - Universidade Federal de Pernambuco, Recife, PE, 1997.

SANTOS, Zila Conceição dos. A Cláusula social dos acordos da OMC Organização Mundial do Comércio - e a proteção internacional do trabalho de competência da OIT - Organização Internacional do Trabalho. 2004. Dissertação (Mestrado em Direito) -Universidade Luterana do Brasil, Canoas, RS, 2004.

SELLA, Adriano. Globalização, neoliberalismo e exclusão social. São Paulo: Paulus, 2002.

SMITH, Adam. Riqueza das Nações. Lisboa: Fundação Calouste Gulbenkian, 1999. v. 1.

THORSTENSEN. Vera. OMC - Organização Mundial do Comércio: as regras do comércio internacional e a rodada do milênio. São Paulo: Aduaneiras, 1999. 